\title{
Gravitational tolerance and size of Brachiosaurus brancai
}

\author{
Bruno Günther ${ }^{1,2}$, Enrique Morgado ${ }^{1,3}$, Karl Kirsch $^{4}$ \& Hanns-Christian Gunga ${ }^{4}$ * \\ With 1 figure
}

\begin{abstract}
In an earlier study, Gunga et al. (1999) determined body size and body volume distribution by photogrammetry in sauropods from the Upper Jurassic in Tendaguru (Tanzania, East Africa). Specifically, they found a body mass of about $74,400 \mathrm{~kg}$ for a specimen of Brachiosaurus brancai. By means of dimensional analysis and a theory of biological similarity, moreover, it was possible to estimate the numerical value of the allometric exponent $(b=-0.17)$ for gravitational tolerance $\left(G_{\max }\right)$ of animals living on earth, which changes with the body mass. This theoretical exponent is close to Economos' empirical finding $(b=-0.14)$. Our results show that there remains an unsolved contradiction between the theoretical assumptions for $G_{\max }$ for the body mass of the largest fully terrestrial animals.
\end{abstract}

Key words: Dinosauria, Sauropoda, body mass estimations, gravitational physiology, g-tolerance, palaeophysiology, evolutionary physiology, photogrammetry.

\section{Zusammenfassung}

In einer vorangehenden Studie (Gunga et al. 1999) wurde mit Hilfe der Photogrammetrie die Körpermassen und Körpervolumenverteilung von jurassischen Sauropoden aus Tendaguru (Tansania, Ostafrika) ermittelt. Diese Bestimmungen ergaben für Brachiosaurus brancai eine Körpermasse von von ca. $74400 \mathrm{~kg}$. Weitere Studien aus der vergleichenden Physiologie haben gezeigt, dass die Toleranz bei Schwerkraftbelastung $\left(G_{\max }\right)$ mit der Körpermasse variert. Durch dimensionale Analyse und vergleichende Studien konnte ein allometrischer Exponent für die Toleranz bei Schwerkraftbelastung mit $b=-0.17$ für terrestrische Organismen bestimmt werden. Dieser theoretische Exponent kommt den empirischen Befunden von Economos $(b=-0.14)$ nahe. Dennoch weisen diese vorliegenden Berechnungen damit auf einen Widerspruch bei den bislang vorhandenen theoretischen Überlegungen zur $\mathrm{G}_{\max }$ bei den grössten maximalen Körpermassen für terrestrisch lebende Organismen hin.

Schlüsselwörter: Dinosauria, Sauropoda, Körpermassenbestimmungen, Gravitationsphysiologie, g-Toleranz, Palaeophysiologie, Evolutionäre Physiologie, Photogrammetrie.

\section{Introduction}

Hypergravity research has shown that small mammals have a greater gravitational tolerance $\left(G_{\max }\right)$ than large ones, as shown already by the earlier studies of Amtmann \& Oyama (1973) and Amtmann (1974) who described this inverse relationship between body size and acceleration tolerance in a comparative study using data derived from rats and humans. Economos (1979) expressed the $G_{\max }$ as an allometric equation:
$\mathrm{Y}=\mathrm{aX}$, where $\underline{Y}$ is any variable of biological interest, $\underline{a}$ is an empirical parameter, $\underline{b}$ the allometric exponent, $\underline{X}$ the reference variable (Huxley 1932). He found that in three small mammals (mouse, rat, and dog) the corresponding equation reads as follows:

$$
\mathrm{G}_{\max }=4 \mathrm{~W}^{-0.14}
$$

where $\mathrm{W}$ is body weight in $\mathrm{kg}$. The correlation is highly significant $(\mathrm{p}=0.0093)$, and the $95 \%$ confidence limits for the slope (b) are -0.115 and

\footnotetext{
1 Programa de Fisiopatología, Facultad de Ciencias Médicas, Universidad de Santiago de Chile, Santiago, Chile.

2 Programa de Fisiología y Biofísica, Instituto de Ciencias Biomédicas, Facultad de Medicina, Universidad de Chile, Santiago, Chile. Chile.

${ }_{3}$ Programa de Fisiopatología, Instituto de Ciencias Biomédicas, Facultad de Medicina, Universidad de Chile, Santiago,

${ }^{4}$ Institut für Physiologie, Zentrum für Weltraummedizin Berlin, Freie Universität Berlin, Arnimallee 22, D-14195 Berlin, Germany.

${ }^{*}$ To whom all correspondence and reprint requests should be adressed. Received January 2002, accepted May 2002
} 
-0.167 . If terrestrial gravity is defined as $1 \mathrm{G}$, a 20-gram mouse tolerates $7 \mathrm{G}$, a 200 -gram rat $5 \mathrm{G}$, a $8-\mathrm{kg} \operatorname{dog} 3 \mathrm{G}$, and a human being of $70 \mathrm{~kg}$ body weight about $2.2 \mathrm{G}$ (the latter value was calculated by means of eqn. 1). From the extrapolation of eqn. 1, Economos (1981) could estimate that the maximal size of land mammals (Indricotherium) should have been about 20 tons, whereby they would barely be able to resist $1 \mathrm{G}$. Hokkanen (1986), on the other hand, studied the upper size limit of terrestrial mammals by using physical arguments as well as allometric laws for bone and muscle strength in animal locomotion. He found that the upper limit of body weight lies between $10^{5}$ and $10^{6} \mathrm{~kg}$. More recently, as mentioned above, Gunga et al. (1999) concluded after a morphometric and physiometric analysis of a Brachiosaurus brancai specimen, mounted and exhibited at the Museum für Naturkunde in Berlin (Janensch 1914, Janensch 1950a, Janensch 1950b), that its body weight should have been $74,420 \mathrm{~kg}$. This noticeable difference in maximal body weight prompted the present study.

\section{Methods}

Based on dimensional analysis and a theory of biological similarity (Günther 1975), it can be assumed that for any function ( $Y$ ), expressed in accordance with the MLT-system of physics
( $M=$ mass, $L=$ length, and $\mathrm{T}=$ time $)$, the following equation allows a quantitative treatment:

$Y=M^{\alpha} \cdot L^{\beta} \cdot T^{\gamma}$

where $\alpha=$ exponent of body mass $(\mathrm{M}), \beta=$ exponent for body length (L), and $\gamma=$ exponent for any time function.

Since the time of Newton, it has been customary to utilize the variable "mass" (M) as the most convenient reference system instead of the original three-dimensional system (MLT) to calculate the "reduced" exponent (b) of all allometric equations. This simplification can be obtained by applying the following two postulates: (1) the constancy of density $\left(M \cdot V^{-1}=1\right.$, or else, $M \cdot L^{-3}=1$ ), which yields $L \alpha M^{1 / 3}$, and (2) the fractal nature of the time dimension $\mathrm{T} \alpha \mathrm{M}^{1 / 4}$ (Sernetz et al. 1985, Günther \& Morgado 1996, and West et al. 1997). When these equivalencies are introduced into equation (2), one obtains:

$\mathbf{Y}=\mathbf{M}^{\alpha+1 / 3 \beta+1 / 4 \gamma}$

Equation (3) represents a general equation of "biological similarity", which is valid for morphometric and physiometric relationships as functions of body mass $(\mathrm{M})$. It is interesting to note that the acceleration of gravity on earth $(G)$ has been always regarded as a parameter with little relevance to biological research. This changed dramatically with the advent of spaceflight. For animals living on earth the acceleration of gravity is a constant $\left(\mathrm{G}=980 \mathrm{cms}^{-2}\right)$, the dimen-

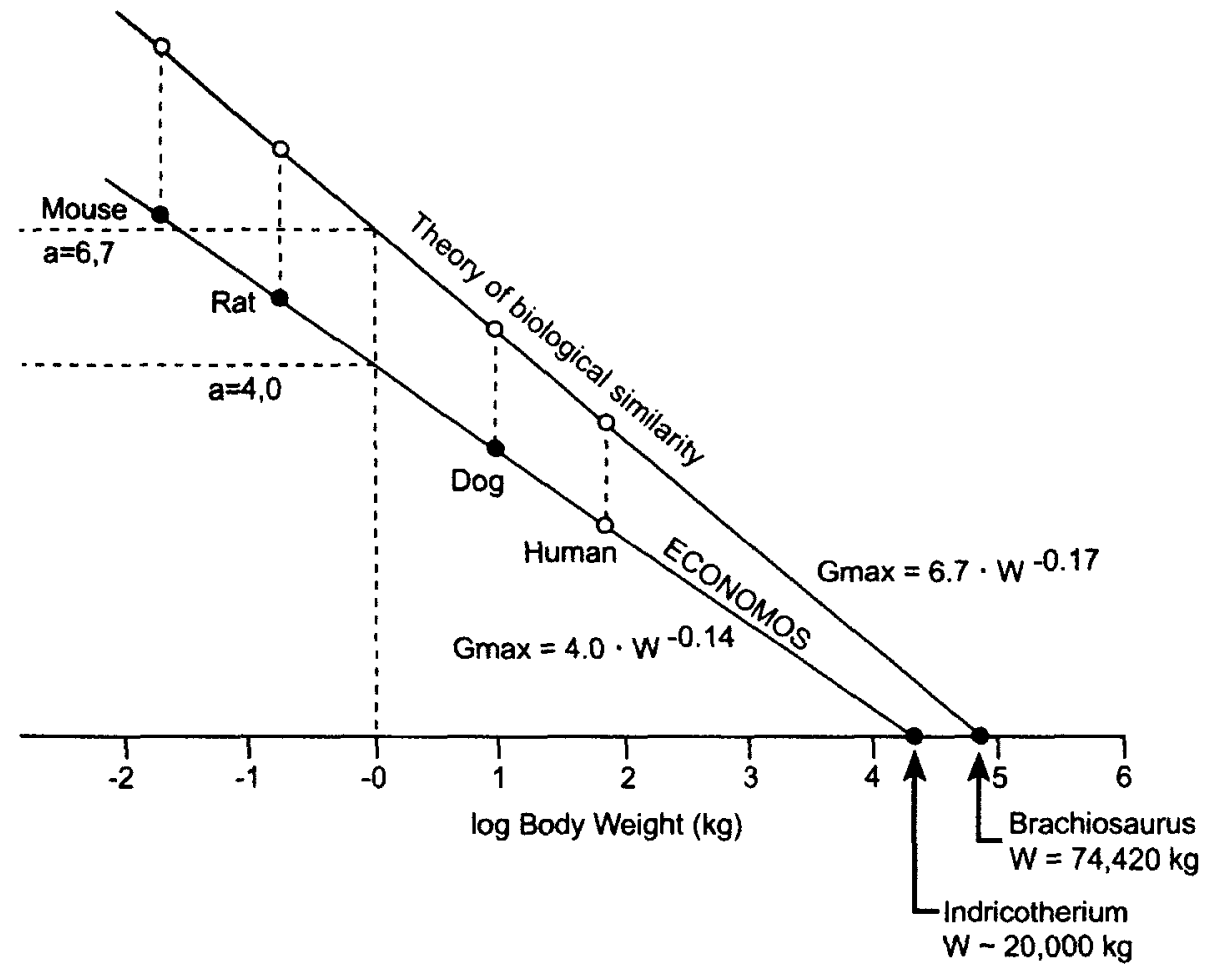

Fig. 1. Double logarithmic plot of $\mathrm{G}_{\max }$ and body weight of Economos' equation

$(b=-0.14)$, and comparison with the theoretical exponent $(b=-0.17)$. The empirical values of $\mathrm{G}_{\max }$ are represented as filled circles, the theoretical ones as open circles. 
sional analysis of which yields $\mathrm{G}=\mathrm{LT}^{2}$. If we analyze gravity as a variable and introduce these exponents into equation (3), the theoretical value for the reduced exponent of $\mathrm{G}$ is:

$b=0.33-0.50=-0.17($ or $b=1 / 3-2 / 4=-1 / 6)$.

\section{Results}

Figure 1 shows the double logarithmic plot of Economos' eqn. 1, based on three experimental values, and the extrapolation for $\mathrm{G}_{\max }=1.0$, which yielded a maximum of $18,840 \mathrm{~kg}$ of weight (W) for Indricotherium. In the same Fig. 1 we have plotted another line based on the theoretically estimated slope of $b=-0.17$ and by utilizing the weight $(74,420 \mathrm{~kg})$ for Brachiosaurus brancai (Gunga et al. 1999) as a reference value for parameter (a). These slope differences (b) seem minute $(-0.14$ versus $-0.17, \Delta=0.03)$. However when the body weight range comprises 5 or even 6 orders of magnitude, the numerical value of parameter (a) varies for $G_{\max }$ from 4.0 (eqn. 1) to $6.7 \mathrm{G}$.

\section{Discussion}

In general, the maximal body mass differences between Economos' (1981) and our postulates at $1 \mathrm{G}$ (earth) are 74,420 and 20,000 , which yields a ratio of 3.7. The slope differences (b) are rather minute $\mathrm{W}^{-0.17}$ and $\mathrm{W}^{-0.14}=\mathrm{W}^{0.03}$ and represent $7.2 \%$ of body mass. The differences between Economos' empirical findings and the present theoretical approach are centered on the two parameters of Huxley's allometric equation: parameter a is until now of an empirical nature and consequently does not affect the theoretical conclusions of the present problem. Exponent (b), on the contrary, can have two origins: a theoretical one (theory of biological similarity), which can be falsified in the Popperian sense by comparing the predicted values with the empirical findings, the second origin of the allometric exponent. Our proposal for the exponent of $\mathrm{b}=-0.17$ lies within the lower limit of the $95 \%$ confidence interval of Economos' slope $(b=-0.14)$, while our parameter a of $6.7 \mathrm{G}$ for the -0.17 slope is located beyond the upper limit (4.31) of the $95 \%$ confidence limit for parameter a of Economos' eqn. 1. However, it must be emphasized here that the present analysis is based on minimal experimental findings: three centrifuge measurements (Economos 1979) and one morphometric study of a single museum specimen (Gunga et al. 1995, Gunga et al. 1999). A possible explanation for the contradiction in the present findings could be that our earlier body mass assumption by the applied photogrammetry method for the Brachiosaurus brancai at the $\mathrm{Mu}$ seum für Naturkunde with about 74 tons is vastly exaggerated and/or based on badly proportioned model, but we think this is not likely for several reasons as outlined in detail below.

When we checked the body mass estimates for the exhibited Berlin Brachiosaurus specimen in the literature we found widely divergent body mass assumptions from 14.9-102 tons, so that body mass estimations on extinct animals seem to be a critical point per se (Lambert 1983, 1993, Paul 1988, Haubold 1990, Weishampel et al. 1992, Christiansen 1997, Alexander 1997). These different estimates were based on projections from models or circumferential measurements of the humerus and femur (Colbert 1962, Lambert 1983, Anderson et al. 1985, Alexander 1989, Peczkis 1994) and the other methods used for body mass estimations in these studies are also prone to criticisms. Specifically, as we have outlined earlier (Gunga et al. 1999) the disadvantage all of these methods lies principally in the use of models, where, depending on the enlargement factor, the most minor inaccuracies can lead to differences with a multiple factor from 10 to 50. Furthermore, if the body mass is calculated by measuring the humerus and femur, it cannot be ruled out that the skeletal material examined actually comes from several different specimens. In addition, there are still numerous gaps in the general comprehension of bone growth in dinosaurs (Reid 1984a, b, Reid 1997, Sander 1999). Extreme strain on the extremities, as occurs with the dynamic load of body mass walking and braking, plays a decisive role physiologically in bone growth. On this basis it is to be expected that the femur/humerus circumference in various species, which normally also differ in their skeletal patterns of movement, i.e. load patterns, does not always correlate necessarily with the body mass; so that with an otherwise equal circumference and cross-sectional surface, the inner structure of bones can vary, for example the corticalis, can be thickened overproportionally in order to increase stability. For this reason our group took a new approach to estimate body mass and body volume of the Brachiosaurus brancai specimen in Berlin by applying photogrammetry to the large scale skeleton. 
Points of reference were mounted on the skeleton for the photogrammetry and a three-dimensional reconstruction was made with stereo projectors. On the basis of these data the probable body contours of the skeletons were added (CAD technique) to calculate the body surface areas and masses. Further details of this new method are given elsewhere (Gunga et al. 1995, Wiedemann \& Wehr 1998, Gunga et al. 1999, Wiedemann et al. 1999). It is important to note that we included for the reconstructions of the probable body contours very recent publications which dealt with the correlations between muscle cross-sectional area and bone because earlier studies might have underestimated the muscle masses which are necessary to move the limbs. As mentioned above, it is a well-known fact that bone architecture depends critically on muscle cross-section and tension development (Frost 1987, Frost 1990a, b, Ferretti et al. 1998). Moreover, bone geometry, e.g. for example the tibia length, influences the geometrical distribution of bone mineral, as it was found that long bones adapted to the same compressive strength are wider than short ones. Rittweger et al. (2000), who investigated images from the lower leg assessed by peripheral quantitative computer tomography in humans, found significant correlations between muscle cross-sectional area and bone. On the average $4 \mathrm{~cm}$ cross-sectional bone area were related to $100 \mathrm{~cm}$ muscle area. According to these findings, and considering thereby that we have to deal with a slow moving tetrapod, our body shape of Brachiosaurus brancai, especially the fore and hindlimbs volumes, actually seem to be a very cautious reconstruction of the body parts and masses of the Berlin specimen of Brachiosaurus brancai.

In conclusion, if we have to assume that these estimations of the body mass of Brachiosaurus brancai are reasonable, we have an unsolved contradiction between the theoretical assumptions for $G_{\max }$ for the body mass of the largest fully terrestrial animals and only future investigations on gravitational tolerance can decide whether our theoretical assumptions, based on Newton's second law, are correct.

\section{References}

Alexander, R. M. 1989. Dynamics of dinosaurs and other extinct giants. 167 pp., Columbia University Press, New York.

- 1997. Engineering a dinosaur. In Farlow, J. O. \& BrettSurmann, M. K.: The Complete Dinosaur. 414-425 pp., Indiana University Press, Bloomington and Indianapolis.
Amtmann, E. 1974. An effect of gravity on the postnatal development of the human and rat femur. - Zeitschrift für Anatomie und Entwicklungsgeschichte 143 (2): $159-83$.

Amtmann, E. \& Omaya, J. 1973. Changes in functional construction of bone in rats under conditions of simulated increased gravity. - Zeitschrift für Anatomie und Entwicklungsgeschichte 139 (3): 307-318.

Anderson, J. F., Hall-Martin, A. \& Russell, D. A. 1985. Long-bone circumference and weight in mammals, birds, and dinosaurs. - Journal of Zoology 207: 53-61.

Christiansen, P. 1997. Locomotion in sauropod dinosaurs. Gaia 14: $45-75$.

Colbert, E. H. 1962. The weights of dinosaurs. - American Museum Novitates 2076: 1-16.

Economos, A. C. 1979. Gravity, metabolic rate and body size of mammals. - Physiologist 22: S71-S72.

- 1981. The largest land mammal. - Journal of Theoretical Biology 89: 211-215.

Ferretti, J. L, Camozza, R. F., Cointry, G. R., Schneider, P., Reimers, C. \& Schiessl, H. 1998. Bone mass is higher in women than in men per unit of muscle mass but bone mechanostat would compensate for the difference in the species. - Bone 23: p. 471.

Frost, H. M. 1987. Bone "mass" and the "mechanostat": a proposal. - Anatomical Record 219: 1-9

- 1990a. Skeletal structural adaptations to mechanical usage (SATMU): 1. Redefining Wolff's law: the bone modeling problem. - Anatomical Record 226: 403-413

- 1990b. Skeletal structural adaptations to mechanical usage (SATMU): 2. Redefining Wolff's law: the remodeling problem. - Anatomical Record 226: 414-422

Gunga, H.-C., Kirsch, K. A., Baartz, F., Röcker, L., Heinrich, W.-D., Lisowski, W., Wiedemann, A. \& Albertz, J. 1995. New data on the Dimensions of Brachiosaurus brancai and their physiological implications. - Naturwissenschaften 82 (4): $189-192$.

Gunga, H.-C., Kirsch, K., Rittweger, J., Röcker, L., Clarke, A., Albertz, J., Wiedemann, A., Mokry, S., Suthau, T., Wehr, A., Heinrich, W.-D. \& Schultze, H.-P. 1999. Body size and body volume distribution in two sauropods from the Upper Jurassic of Tendaguru (Tanzania). - Mitteilungen aus dem Museum für Naturkunde Berlin, Geowissenschaftliche Reihe 2: 91-102.

Günther, B. 1975. Dimensional analysis and theory of biological similarity. - Physiological Reviews 55: 659-699.

Günther, B. \& Morgado, E. 1996, Duality in physiological time: Euclidean and fractal. - Biological Research 29: 305-311.

Haubold, H. 1990. Die Dinosaurier. System, Evolution, Paläobiologie. (4. Aufl.). 248 pp., A. Ziemsen Verlag, Wittenberg.

Hokkanen, J. E. I. 1986. The size of the largest land animals. - Journal of Theoretical Biology 118: 491-499.

Huxley, J. S. 1932. Problems of Relative Growth. 312 pp., Dover Publications, London and New York.

Janensch, W. 1914. Bericht über den Verlauf der TendaguruExpedition. - Archiv für Biontologie 3 (1): 17-58.

- 1950a. Die Wirbelsäule von Brachiosaurus brancai. - Palaeontographica, Suppl. 7 (1, Teil 3): 27-92.

- 1950b. Die Skelettrekonstruktion von Brachiosaurus brancai. - Palaeontographica, Suppl. 7 (1, Teil 3): 95-103.

Lambert, D. 1983. A Field Guide to Dinosaurs: 256 pp., Avon, New York.

- 1993. The Ultimate Dinosaur Book: 192 pp., Dorling Kindersley Inc., London.

Paul, G. S. 1988. The brachiosaur giants of the Morrison and Tendaguru with description of a new subgenus, Giraffatitan, and a comparison of the world's largest dinosaurs. Hunteria 2 (3): 1-14.

Peczkis, J. 1994. Implications of body-mass estimates for dinosaurs. - Journal of Vertebrate Paleontology 14: $520-533$. 
Reid, R. E. H. 1984a. Primary bone and dinosaurian physiology. - Geological Magazine 121: 589-598.

- 1984b. The histology of dinosaurian bone and its possible bearing on Dinosaurian physiology. - Symposium of the Zoological Society London 52: 629-663.

- 1997. Dinosaurian physiology: The case for "intermediate" dinosaurs. In Farlow, J. O. \& Brett-Surmann, M. K. (eds): The Complete Dinosaur. 449-473 pp., Indiana University Press, Bloomington and Indianapolis.

Rittweger, J., Wilhelm, G., Ehrig, J., Jung, C., Koch, U., Ramolla, J., Schmidt, F., Newitt, D., Majumdar, S., Schiessl, H. \& Felsenberg, D. 2000. Bone-muscle strength indices for the human lower leg. - Bone 27 (2): 319-326.

Sander, P. M. 1999. Life history of Tendaguru sauropods as inferred from long bone histology. - Mitteilungen aus dem Museum für Naturkunde Berlin, Geowissenschaftliche Reihe 2: 103-112.
Sernetz, M., Gelléri, B. \& Hoffmann, J. 1985. The organism as a bioreactor. Interpretation of the reduction law of metabolism in terms of heterogeneous catalysis and fractal structure. - Journal of Theoretical Biology 117: 209-239.

Weishampel, D. B., Dodson, P. \& Osmólska, H. (eds) 1992. The Dinosauria. $733 \mathrm{pp}$., University of California Press, Berkeley, Los Angeles.

West, G. B., Brown, J. H. \& Enquist, B. J. 1997. A general model for the origin of allometric scaling laws in biology. - Science 276: 122-126.

Wiedemann, A. \& Wehr, A. 1998. Vermessung von Dinosaurierskeletten mit Stereophotogrammetrie und Laserscanner. - Publikationen der Deutschen Gesellschaft für Photogrammetrie und Fernerkundung 6: 301-308.

Wiedemann, A., Suthau, T. \& Albertz, J. 1999. Photogrammetric survey of dinosaur skeletons. - Mitteilungen aus dem Museum für Naturkunde Berlin, Geowissenschaftliche Reihe 2: 113-119. 